\title{
COMO DOUTORANDOS EM LINGUÍSTICA CONSTROEM A SEÇÃO "IDENTIFICAÇÃO DO PROBLEMA DE PESQUISA"1
}

\section{HOW PHD STUDENTS IN LINGUISTICS CONSTRUCT THE SECTION "IDENTIFICATION OF THE RESEARCH PROBLEM}

Recebido: 15/03/2021

Aprovado: 21/06/2021

Publicado: $30 / 07 / 2021$

DOI: $10.18817 /$ rlj.v5i01.2526

\begin{abstract}
Tâmara Ramalho da Silva ${ }^{2}$ Orcid ID: https://orcid.org/0000-0003-0684-379X Tristan Nathanael Veras Pedrosa ${ }^{3}$ Orcid ID: https://orcid.org/0000-0002-1815-0053 Francisco Alves Filho 4 Orcid ID: https://orcid.org/0000-0002-2284-4197
\end{abstract}

\begin{abstract}
Resumo: Este artigo tem como objetivo analisar a seção "Identificação do Problema de Pesquisa" dos projetos de pesquisa de doutorandos em Linguística, descrevendo os passos retóricos recorrentes usados pelos produtores do gênero. Nosso corpus é composto por doze projetos de pesquisa submetidos e aprovados na seleção de doutorado (para ingresso em 2019) do Programa de Pós-Graduação em Letras (PPGEL) da Universidade Federal do Piauí (UFPI). O estudo em questão tem como base a abordagem sociorretórica de gêneros de Swales (1990), Miller (2012) e Bazerman (2005). Para a análise do corpus, primeiramente realizamos a leitura integral dos projetos de pesquisa a fim de que pudéssemos compreender do que tratava cada projeto. Em seguida, nos dedicamos particularmente à leitura da seção de "Identificação do problema de pesquisa" para, a partir disso, identificarmos os passos retóricos, sempre observando as pistas linguísticas que levaram à sua concretização. A partir da análise, evidenciamos a recorrência de quinze passos retóricos. A seção analisada se mostrou bastante heterogênea, servindo como uma "porta de entrada", apresentando estratégias de aspectos teóricos, metodológicos e empíricos. Assim, os pesquisadores parecem se apropriar de conhecimentos teóricos disponíveis e articulá-los com suas experiências a fim de apresentar uma problemática.
\end{abstract}

Palavras-chave: Projeto de pesquisa. Gêneros acadêmicos. Análise de gêneros.

Abstract: This research aims to analyze the section "Identification of the Research Problem" of the research projects of PhD students in Linguistics, describing the recurrent rhetorical steps used by the producers of the genre. Our corpus is composed of twelve research projects submitted and approved in the doctoral selection (for admission in 2019) of the Postgraduate Program in Letters of the Federal University of Piauí. This study is based on the socio-rhetorical approach to genres by Swales (1990),

\footnotetext{
${ }^{1}$ Artigo fruto de pesquisas desenvolvidas no Programa Institucional de Bolsas de Iniciação Científica.

${ }^{2}$ Graduanda em Letras pela Universidade Federal do Piauí. Integra o Núcleo de estudos em texto, gênero e discurso (CATAPHORA), na UFPI. Foi pesquisadora bolsista no Programa Institucional de Bolsas de Iniciação Científica (PIBIC/UFPI) e no Programa Institucional de Bolsas de Iniciação à Docência (PIBID). Atualmente investiga 0 gênero projeto de pesquisa. E-mail: tamara.ramalho25@gmail.com
}

${ }^{3}$ Graduando em Letras pela Universidade Federal do Piauí. Integra o Núcleo de estudos em texto, gênero e discurso (CATAPHORA), na UFPI. Foi pesquisador bolsista no Programa Institucional de Bolsas de Iniciação Científica (PIBIC/CNPq) e no Programa Institucional de Bolsas de Iniciação à Docência (PIBID). E-mail: tristanveras66@hotmail.com

4 Professor doutor associado da Universidade Federal do Piauí - UFPI. Coordena o Núcleo de Pesquisa CATAPHORA, através do qual coordena uma pesquisa, com financiamento do CNPQ, sobre letramento acadêmico com foco na escrita de projetos de pesquisa. É membro do comitê de Assessoramento Técnico-Científico do PIBIC/UFPI e do comitê de Pós-Graduação (UFPI). E-mail: chicofilhoo@ufpi.edu.br 
Miller (2012) and Bazerman (2005). For the analysis of the corpus, we first performed a full reading of the research projects so that we could understand what each project was about. Then, we dedicate ourselves particularly to reading the section "Identification of the research problem" in order to, from that, identify the rhetorical steps, always observing the linguistic clues that led to its realization. From the analysis, we showed the recurrence of fifteen rhetorical steps. The analyzed section proved to be quite heterogeneous, serving as a "gateway", presenting strategies of theoretical, methodological and empirical aspects. Thus, researchers seem to appropriate the available theoretical knowledge and articulate it with their experiences in order to present a problem.

Keywords: Research project. Academic genres. Genre analysis.

\section{Introdução}

Pesquisadores, iniciantes ou experientes, estão sempre em contato com o gênero projeto de pesquisa. Na graduação, o projeto de pesquisa geralmente é uma etapa obrigatória para dar prosseguimento à realização da monografia de conclusão do curso. Na pós-graduação, para se obter uma vaga no mestrado ou no doutorado, os participantes devem submeter um projeto de pesquisa, sendo essa uma etapa eliminatória do processo seletivo. Além disso, pesquisadores valem-se desse gênero quando buscam financiamento para pesquisas.

O projeto de pesquisa é composto por seções, as quais podem apresentar variações quanto à denominação, dependendo do edital de seleção, da cultura disciplinar na qual se insere, do caráter do objeto de estudo e até mesmo do pesquisador. Dentre as seções que compõem um projeto de pesquisa, a seção "Identificação do problema de pesquisa" é responsável por apontar o caminho que o pesquisador irá percorrer em seu estudo; nela, portanto, o problema de pesquisa é definido. Nesta seção, o autor pode também indicar o porquê de seu estudo ser relevante, ou seja, convencer que ele merece ser aprovado pela banca avaliadora.

Apesar de o projeto de pesquisa ser imprescindível no meio acadêmico, ainda há, no Brasil, poucos trabalhos voltados para a análise da organização retórica desse gênero. Em vista disso, o Núcleo de Pesquisa Cataphora tem investigado o gênero projeto de pesquisa desde 2014, já tendo sido analisada a seção de justificativa (SILVA e ALVES FILHO, 2020; ALVES FILHO, 2018), a seção de metodologia (MONTEIRO, 2016), a seção de fundamentação teórica (RIO LIMA, 2016), assim como a seção Identificação do problema de pesquisa (SILVA, ALVES FILHO e OLIVEIRA 2020; OLIVEIRA e ALEXANDRE, 2020). Além disso, foram analisados passos específicos, sendo eles "Relatando pesquisa prévia", "Indicando 
lacuna de pesquisa" e "Indicando problemas do mundo real" (ALVES FILHO e RIO LIMA, 2020; RIO LIMA, 2019).

Partindo dessas informações, neste artigo buscamos identificar e descrever os passos retóricos mais recorrentes na seção "Identificação do Problema de Pesquisa" dos projetos de pesquisa de doutorandos de Linguística. Nossa problemática de pesquisa é compreender como doutorandos na área de Linguística agem retoricamente quando escrevem a seção referida. O corpus deste trabalho é composto por doze projetos de pesquisa submetidos e aprovados na seleção de doutorado (para ingresso em 2019) do Programa de Pós-Graduação em Letras (PPGEL) da Universidade Federal do Piauí (UFPI).

Visto que a maioria das pesquisas que se dedicam à análise do gênero projeto de pesquisa, sobretudo as desenvolvidas no núcleo Cataphora, se empenham em investigar diferentes seções do gênero em projetos de mestrandos, buscamos neste estudo contribuir ampliando as investigações sobre o gênero projeto de pesquisa, afinal, até o presente momento no Brasil não foram encontrados trabalhos que analisassem a organização retórica da seção "Identificação do problema de pesquisa" em projetos de doutorandos de Linguística. Nesse sentido, pode-se afirmar que esta pesquisa insere-se para contribuir e complementar as descobertas de Oliveira (2019) que analisou esta seção projetos de mestrandos de Linguística.

\section{Gêneros textuais}

Os gêneros, na acepção da retórica clássica, eram definidos através dos seus aspectos formais (MARCUSCHI. 2008). Esta concepção formalista, segundo Alves Filho (2011, p. 18), fez muitos acreditarem que "o gênero seria apenas uma forma para classificar os textos de acordo com sua estrutura de composição".

Apenas a partir do início do século $X X$, os gêneros passaram a ser definidos de outra maneira, cabendo citar a importância das contribuições de Bakhtin (2016, p. 12), para o qual os gêneros seriam "tipos relativamente estáveis de enunciados". Sob influência da abordagem bakhtiniana, na década de 1980, os estudos da sociorretórica deram seus primeiros passos, encaminhando-se para uma abordagem funcionalista, que leva em conta as situações de uso dos gêneros. Dentre os 
teóricos que seguem essa abordagem, tomaremos como base as contribuições de: Swales (1990), Miller (2012) e Bazerman (2005).

Tendo isso em vista, Swales (1990) propôs um conceito de gênero, partindo da problemática de enxergá-lo apenas como uma fórmula textual, visão esta que influía negativamente no ensino. No conceito proposto, Swales buscou, de forma eclética, suporte em quatro campos de estudos, sendo eles: os estudos do folclore, da literatura, da linguística e da retórica.

Influenciado por esses quatro campos do conhecimento, o autor elencou cinco características importantes para a constituição dos gêneros: a ideia de classe de eventos comunicativos, o propósito comunicativo, a prototipicidade, a lógica subjacente aos gêneros e a terminologia. A partir dessas características, Swales (1990, p. 58) define o gênero como "uma classe de eventos comunicativos, em que os seus exemplares compartilham propósitos comunicativos". Nesse sentido, o propósito comunicativo de um gênero é estabelecido através dos membros experientes da comunidade discursiva e representa a razão do gênero, que o molda esquematicamente, influenciando seu conteúdo e estilo. Além disso, os gêneros são dotados de nomenclaturas que são atribuídas pelas próprias comunidades discursivas.

Em conformidade com uma abordagem sociorretórica para a definição de gênero, Miller (2012) analisa a ligação entre o gênero e uma situação recorrente e de que forma o gênero representa uma ação retórica tipificada. Ela observa que a recorrência não está em uma situação material, mas no que interpretamos dos tipos de situações existentes. Dessa forma, "a comunicação bem-sucedida requer que os participantes compartilhem tipos comuns" (MILLER, 2012, p. 30). De forma análoga, Bazerman (2005, p. 31) afirma que os gêneros são "fenômenos de reconhecimento psicossocial que são parte de processos de atividades socialmente organizadas".

Nesse sentido, a fim de analisar a organização retórica de um gênero acadêmico, é importante levar em conta os conceitos de: propósitos comunicativos, movimentos e passos retóricos. Inicialmente, Swales (1990) concebia o propósito comunicativo como um critério privilegiado na análise de gêneros, determinando a sua estrutura esquemática, o seu conteúdo e estilo. Contudo, o autor reconhecia dificuldades em torno da sua identificação. Isso porque a identificação do propósito comunicativo se ampara na opinião de membros experientes de uma comunidade discursiva e estes nem sempre estão em consenso. Logo, é um critério de difícil 
identificação, pois muitas vezes pode estar implícito em um gênero ou podem ser reconhecidos mais de um propósito para o mesmo gênero.

Em busca de solucionar a problemática da difícil identificação do propósito, Askehave e Swales (2009) afirmam que seria mais adequado abandonar o propósito comunicativo como método imediato de classificação dos discursos em categorias genéricas, o que não impede que o analista continue considerando o conceito como significante no resultado final.

No que diz respeito ao movimento retórico, Swales (2004, p. 228) o define como "uma unidade discursiva ou retórica que desempenha uma função comunicativa coerente em um discurso escrito ou falado", isto é, realiza uma função que contribui para a construção da totalidade e a realização dos propósitos comunicativos do texto. De modo semelhante, Motta-Roth (1995, p. 61 apud HENDGES, 2001, p. 11) define o movimento retórico como "um bloco de texto que pode se estender por mais de uma sentença, realizando uma função comunicativa específica". A autora acrescenta, ainda, que um conjunto de movimentos constitui a totalidade da estrutura informacional que deve ser contemplada no texto para que ele possa ser reconhecido como exemplar de um determinado gênero.

O passo retórico, por sua vez, é considerado uma subunidade do movimento retórico. Ou seja, o movimento retórico é composto por unidades menores que retêm de maneira específica uma função retórico-comunicativa. Isso implica dizer que o passo retórico representa a função retórico-comunicativa "desempenhada por uma sequência textual particular a qual, para gozar deste status, precisa ser recorrente numa seção típica de um gênero" (ALVES FILHO, 2018, p. 139).

Dentre os estudos que envolvem a organização retórica de gêneros acadêmicos, aquele que, possivelmente, mais influenciou seus sucessores foi o de Swales com o modelo CARS (create a reseach space). Constantemente renovado, estudiosos da área de gêneros textuais o tem adaptado e aplicado a diferentes gêneros em diferentes contextos de pesquisa. Em relação às pesquisas que aplicaram e adaptaram o modelo proposto por Swales (1990) para a análise de projetos de pesquisa, cabe citar a de Rio Lima (2019), a respeito dos passos retóricos (relatando pesquisas prévias, indicando lacuna de pesquisa e problemas do mundo real), tendo concluído que o ponto de partida para a produção de projetos de linguística estão mais ancorados em problemas do mundo real. Também vale mencionar a pesquisa de Oliveira (2019) sobre seção "Identificação do problema de 
pesquisa" em projetos de pesquisa de mestrandos de Linguística, tendo sua análise revelado os nove passos mais recorrentes na seção, sendo que um deles (o passo Levantando hipóteses) ainda não tinha sido descrito anteriormente.

\section{0 gênero projeto de pesquisa e a Identificação do problema de pesquisa}

Em sua obra que trata da escrita de gêneros acadêmicos, Motta-Roth e Hendges (2010, p. 55) afirmam que o projeto de pesquisa é "[..] um planejamento do que vamos fazer para investigar um determinado problema", ao passo que Gil (2002, p. 19), em seu manual, caracteriza o projeto como fruto concreto do planejamento, sendo, portanto, um "[..] documento explicitador das ações a serem desenvolvidas ao longo do processo de pesquisa". Assim, notamos que as noções têm em comum a ideia de projeto como um instrumento para organizar as ações para o desenvolvimento da pesquisa.

É importante conceber o projeto de pesquisa como algo flexível, pois é construído e reconstruído a partir da interação do pesquisador e o seu objeto de estudo, e também porque essa interação pode vir a processar mudanças tanto no pesquisador quando no seu objeto de estudo, ganhando novas direções (BARROS, 2005). Além de ser norteador da pesquisa, o projeto caracteriza-se por ser um instrumento de avaliação, sendo parte das exigências nas seleções para ingresso na pós-graduação em nível de mestrado e doutorado. Nesse sentido, é notório que há uma escrita persuasiva nos projetos, mesmo que implícita, seja para ingresso na pós-graduação, como exemplificado anteriormente, ou para qualquer outra instituição para a qual o pesquisador vá submeter o seu projeto.

\footnotetext{
Os pré-projetos de pesquisa submetidos à seleção de pós-graduação também compartilham essa natureza geral persuasiva, nesse caso visando persuadir a banca examinadora de que a proposta atende ao edital e às linhas de pesquisa do programa e oferece indícios de que o seu autor possui mérito acadêmico para ingressar num curso de pós-graduação (ALVES FILHO, 2018, p. 134).
}

Uma das seções que compõe o projeto de pesquisa é a de "Identificação do problema de pesquisa", a qual pode receber outros nomes. Segundo Gil (2002, p.20) não há regras fixas que delimitem como deve ser a elaboração de um projeto de pesquisa. O tipo de problema e o estilo do pesquisador são responsáveis por determinar a estrutura. Uma vez que o problema guia o estudo, Gil (2002) propõe 
que a primeira seção do projeto seja destinada à apresentação do problema. Também de acordo com o edital de seleção ao PPGEL/UFPI, esse espaço é destinado à caracterização do problema.

A expectativa é que nesta seção haja a definição e caracterização, com apoio na bibliografia específica, do problema a ser investigado. O problema deve traduzir o âmago da investigação, em função do qual as outras seções se estruturam (EDITAL № 03/2018, p. 12).

A partir das informações apresentadas no edital, percebemos que a seção de identificação do problema de pesquisa é tida como basilar do projeto de pesquisa, convergindo com a ideia de Barros (2005, p. 189), que apresenta a seção em questão (por ele nomeada de "delimitação temática") como essencial, dado que dela se desdobrarão todas as outras. Ademais, Salomon (1996, apud MOTTA-ROTH; HENDGES, 2010) afirma que essa seção é responsável também por delimitar teórico e operacionalmente o problema que será investigado, apontando as dificuldades e as lacunas encontradas no conhecimento atual.

\section{Metodologia}

O corpus desta pesquisa é formado por 12 projetos de pesquisa submetidos e aprovados na seleção para o programa pós-graduação em Letras (PPGEL), em nível de doutorado, na área de Linguística da Universidade Federal do Piauí - UFPI, para ingresso no ano de 2019. Os projetos foram cedidos pelos autores e estão inseridos nas seguintes linhas de pesquisa: Texto, discurso e gêneros como práticas sociais; Gramática e Léxico - descrição e ensino; Variação linguística, oralidade e letramentos. Todos os projetos coletados passaram pela avaliação e aprovação de professores experientes da banca avaliadora. Visando o anonimato, os nomes dos autores e os títulos dos projetos foram ocultados. Assim, adotamos uma codificação alfanumérica para identificar os projetos.

Seguimos a proposta de Alves Filho (2018), que abandona a noção de movimento retórico e trabalha apenas com os passos retóricos, uma vez que considera os passos como uma categoria localizável no texto e menos abstrata que o movimento retórico. Assim como Oliveira (2019), analisamos a seção "Identificação do problema de pesquisa" partindo de passos retóricos descritos por pesquisadores do núcleo Cataphora para outras seções do gênero projeto de pesquisa, tais como: 
a seção de justificativa de projetos de Linguística (ALVES FILHO, 2018); a de metodologia de projetos de Linguística (MONTEIRO, 2016); e de fundamentação teórica de projetos de História (RIO LIMA, 2016). Incorporamos também a contribuição de Oliveira (2019) que descreveu o passo "levantando hipóteses" para a seção analisada.

A pesquisa em questão foi construída a partir da leitura integral do corpus, para que pudéssemos compreender do que tratava cada projeto de pesquisa. Em seguida, nos dedicamos particularmente à leitura da seção de "Identificação do problema de pesquisa". Posteriormente, buscamos, através da análise textual, identificar os passos retóricos, sempre observando as pistas linguísticas que levassem à concretização dos passos. Após a identificação, catalogamos todos os passos retóricos encontrados na amostra. Houve passos que apareceram mais de uma vez, de forma intercalada, em um determinado projeto. Nesse caso, consideramos cada aparição como uma nova ocorrência.

\section{Resultados e discussão}

Nesta parte do trabalho, analisamos a organização retórica da seção de "Identificação do problema de pesquisa", apresentando os passos retóricos mais recorrentes e comparando-os com os elementos tidos como característicos da seção, de acordo com as informações contidas nos manuais de escrita acadêmica.

\subsection{Organização retórica de seção de "Identificação do problema de pesquisa" de projetos de pesquisa na área de Linguística}

Elencamos um conjunto de passos retóricos utilizados pelos doutorandos para a construção da seção identificação do problema de pesquisa. Dentre esses passos, selecionamos os que apresentam ocorrência igual ou superior a 3 (25\% ou mais), que são os seguintes: 
Quadro 1- Visão geral dos passos nos projetos analisados.

\section{Nome do passo \\ Ocorrências \\ Quantidade \\ Recorrência de projetos}

P1 Formulando questões norteadoras da pesquisa

\begin{tabular}{llll}
\hline $\begin{array}{l}\text { P2 Apresentando objetivos da } \\
\text { pesquisa }\end{array}$ & 10 & $9 / 12$ & Alta \\
\hline $\begin{array}{l}\text { P3 Indicando a filiação teórica da } \\
\text { pesquisa }\end{array}$ & 10 & $6 / 12$ & Média \\
$\begin{array}{l}\text { P4 Reivindicando a relevância do } \\
\text { objeto de estudo }\end{array}$ & 9 & $6 / 12$ & Média \\
\hline P5 Definindo conceitos & 8 & $4 / 12$ & Média \\
\hline $\begin{array}{l}\text { P6 Indicando problemas no mundo } \\
\text { social }\end{array}$ & 7 & $4 / 12$ & Média \\
\hline P7 Levantando hipóteses & 7 & $5 / 12$ & Média \\
\hline P8 Explicando um fenômeno & 6 & $3 / 12$ & Baixa \\
\hline P9 Relatando pesquisa prévia & 5 & $3 / 12$ & Baixa \\
\hline P10 Indicando possíveis benefícios & 5 & $4 / 12$ & Média \\
\hline $\begin{array}{l}\text { P11 Delimitando corpus e/ ou fonte } \\
\text { do corpus da pesquisa }\end{array}$ & 4 & $4 / 12$ & Média \\
\hline P12 Indicando lacuna da pesquisa & 3 & $2 / 12$ & Baixa \\
\hline $\begin{array}{l}\text { P13 Recomendando e/ou } \\
\text { prescrevendo ação empírica }\end{array}$ & 3 & $3 / 12$ & Baixa \\
$\begin{array}{l}\text { P14 Indicando a(s) categoria(s) de } \\
\text { análise }\end{array}$ & 3 & $2 / 12$ & Baixa \\
\hline $\begin{array}{l}\text { P15 Justificando seleção do corpus, } \\
\text { fontes ou sujeitos }\end{array}$ & 3 & $3 / 12$ & Baixa \\
\hline $\begin{array}{l}\text { Fonte: Elaborado pelos autores (2021). } \\
\text { Ponara }\end{array}$ & & &
\end{tabular}

A partir das análises, assim como na pesquisa de Oliveira (2019), constatamos que os doutorandos, ao construírem a seção de "Identificação do problema de pesquisa", fazem uso de um mesmo passo retórico mais de uma vez, de forma que, mesmo fazendo uso de uma variedade de passos retóricos, apenas os que apresentam um grau de recorrência alto (P1 e P2) estão presentes na maior parte da amostra, enquanto que os demais estão concentrados em poucos exemplares da amostra. Dessa forma, vemos que nenhum dos passos retóricos encontrados está presente em todos os projetos, de forma que não podemos falar em passos obrigatórios para a construção da seção analisada presente nos projetos desta amostra. Assim, percebemos que os escritores não detêm uma visão consensual quanto à realização retórica da seção, o que a torna bem heterogênea. 
Além disso, assim como em Alves Filho (2018), para a seção de justificativa, e em Oliveira (2019), para a seção de "Identificação do problema de pesquisa", não encontramos nenhum caso em que duas seções apresentem os mesmos passos retóricos ordenados numa mesma sequência.

\subsection{Passos retóricos}

O passo Formulando questões norteadoras de pesquisa foi o mais recorrente entre os passos encontrados, apresentando quatorze ocorrências em onze projetos (dos 12 analisados). Este passo é utilizado para apresentar questionamentos que nortearão a pesquisa e pode ser concretizado por meio de uma ou mais perguntas, formando uma cadeia de questionamentos. Geralmente é realizado por meio de frases interrogativas diretas, mas também aparece por meio de perguntas implícitas, apenas com um tom interrogativo.

As principais pistas linguísticas típicas deste passo foram: "surge o seguinte problema", "as seguintes questões norteadoras", "as principais indagações", "questiona-se", "surge o questionamento", "nos propomos a descobrir".

A seguir, temos alguns trechos para exemplificar:

E, nesse cenário, surge o seguinte problema: Como a fundamentação teórica da Análise de Discurso pode ser utilizada para a produção de uma proposta para o ensino, em escola pública, de leitura de gêneros jornalístico-midiáticos em aulas de Língua Portuguesa no Ensino Médio?

02AD2019

Em 02AD2019, o passo é realizado por meio de uma frase interrogativa direta. De maneira semelhante, em 01LTX2019, a realização dele se dá de forma direta, mas se estrutura em uma cadeia de questionamentos. Esta foi a maneira mais recorrente de se formular questões norteadoras de pesquisa no corpus, justificando assim, a longa extensão desse passo. Nesse sentido, algumas de suas ocorrências chegam a ter mais de cem palavras, demostrando que a realização do passo em questão é muito importante para o desenvolvimento da seção e do projeto de pesquisa. 
As principais indagações que fomentam o problema de investigação desta proposta são os seguintes: há diferenças entre os modos de organização retórica de projetos de doutorado nas áreas de Educação e Políticas Públicas que possam ser tomados como indícios da existência de duas culturas disciplinares distintas? Quais os sistemas de gêneros de leitura e escrita presentes nas duas áreas de pesquisa? Como e com quem os doutorandos interagem antes e durante 0 processo de elaboração de seus projetos de doutorado? Que eventos deflagradores são utilizados nas duas áreas para o desenvolvimento da proposta de pesquisa?

01LTX2019

Em 06AD2019, o passo não é realizado por meio de uma interrogativa direta. Note que o autor coloca uma série de pontos a serem investigados.

Diante disso faz-se necessário investigar no gesto de elaborar e disponibilizar as disciplinas nos ambientes virtuais, como professores formadores vêem essa modalidade de educação através das marcas ou pistas deixadas na superfície textual dessas disciplinas, que sentidos produzem para 0 ato pedagógico de conduzir uma disciplina em um AVA (ambiente virtual de aprendizagem), que imagens produzem de si em e por esses discursos.

06AD2019

Ao analisar a realização do passo Formulando questões norteadoras da pesquisa, atentamos se os questionamentos foram formulados pelo próprio pesquisador ou se ele trouxe questionamentos de outros autores. Evidenciamos que, aparentemente, os pesquisadores constroem suas próprias indagações de pesquisa, resultado de observações da vida prática e de estudos teóricos.

O passo retórico Apresentando objetivos da pesquisa foi o segundo mais recorrente, totalizando dez ocorrências em nove projetos (dos 12 analisados). Ele é utilizado para apresentar os objetivos da pesquisa. Mesmo que o projeto de pesquisa disponha de uma seção própria para tratar dos objetivos, constatamos que é muito comum que os doutorandos façam uso desse passo logo na seção de "Identificação do problema de pesquisa", provavelmente por questões persuasivas, colocando os objetivos para justificar a realização da pesquisa ou apontar caminhos para resolução da problemática de estudo. Como bem explica Alves Filho (2018, p.149), "é muito provável que a reiteração dos objetivos em mais de uma seção assuma um caráter persuasivo, tendo em vista que informações repetidas possuem um status de relevância acentuada". 
Assim, comparamos os objetivos descritos na seção analisada com a seção que se destina à apresentação dos objetivos (gerais e específicos) e pudemos constatar que os doutorandos fazem de fato uma reiteração, por meio de paráfrases. As principais pistas linguísticas que indicam o reconhecimento deste passo são: "tem por objetivo", "esta pesquisa propõe", "intenta responder", "tem o intuito de" e "com o objetivo de". Veja um exemplo:

Esta pesquisa tem por objetivo compreender, levando em conta o contexto de produção e recepção, os processos intelectuais que caracterizam o estabelecimento da Linguística no Piauí, bem como analisar continuidades e descontinuidades no desenvolvimento do conhecimento no período de implantação e constituição de instituições e grupos que possibilitaram o desenvolvimento e consolidação da Linguística no estado.

03GL2019

O passo Indicando filiação teórica de pesquisa apresentou dez ocorrências em seis projetos de pesquisa. É utilizado para indicar em qual campo teórico a pesquisa se insere e pode ser desenvolvido por meio da própria indicação do campo ou de autores específicos da teoria. No geral, este passo retórico é desenvolvido em poucas palavras. As pistas linguísticas que permitem sua identificação são as menções às subáreas de pesquisa ou aos autores teóricos, como no exemplo abaixo:

À guisa das contribuições da Análise de Discurso francesa, este projeto de pesquisa está subsidiado em autores como Pêcheux (1990), (1999); Indursky (2003); Orlandi (2007), (2008), (2012a), (2012b), (2014), entre outros caros à discussão.

07AD2019

É importante lembrar que o projeto de pesquisa possui uma seção específica para tratar de aspectos teóricos, nesta amostra chamada de fundamentação teórica. Logo, a realização desse passo ainda na seção de Identificação do problema de pesquisa indica uma clara relevância para o aporte teórico na construção do problema de pesquisa. Com isso, o pesquisador constrói a imagem de alguém que "está por dentro" das bases teóricas que o ajudarão a explicar determinado fenômeno, resolver ou amenizar as questões-problemas. 
O passo Reivindicando a relevância do objeto de estudo apresentou nove ocorrências em seis projetos de pesquisa. Ele é utilizado para expor observações que valorizem o objeto de estudo e indiquem que ele possui algum tipo de relevância (social, cultural, educacional, teórica etc). Tal passo apresenta caráter persuasivo, uma vez que os doutorandos precisam convencer a banca avaliadora de que o seu objeto de estudo é relevante e merece ser pesquisado. As pistas linguísticas que indicam o reconhecimento desse passo são expressões lexicais que indicam valoração, como: "é importante", "é que se vale", "é relevante". A seguir, veja alguns exemplos

O modo como as bancas examinadoras, ao longo dos anos, elaboraram a prova coloca-nos no campo da (ir) repetibilidade em que os discursos sobre denúncias sociais circularizam socialmente. A cada nova formulação, emanam efeitos de sentido que transcendem a história, perpassam a ideologia e deslizam na opacidade do discurso. Por essa modulação de sentidos ora velados, ora silenciados, ora discursivizados em forma de protesto é que se vale o investimento nessa pesquisa.

07AD2019

Em 07AD2019, o autor apresenta pontos que tornam seu objeto de estudo relevante, reivindicando a importância de sua pesquisa ter investimento. Assim como em 01LTX2019 que apresenta o seu objeto de estudo (gênero projeto de pesquisa) como relevante, uma vez que é exigido como requisito para financiamentos de pesquisa. Interessante que o autor está demostrando para a banca que a sua pesquisa é relevante porque busca estudar o instrumento que o mesmo está desenvolvendo com a finalidade de adentrar no doutorado.

O gênero projeto de pesquisa desempenha um papel relevante em praticamente todas as culturas disciplinares, uma vez que financiamentos de pesquisa, via de regra, exigem a apresentação de um projeto.

01LTX2019

O passo Definindo conceitos apresentou oito ocorrências em quatro projetos de pesquisa. Descrito originalmente em Alves Filho (2018), para quem o passo caracteriza-se por ser eminentemente teórico, uma vez que é utilizado para apresentar conceitos de base teórica e que ajudarão na compreensão da pesquisa. 
Tais conceitos podem ser definidos a partir de uma citação direta ou indireta, exibindo como a categoria é definida por um autor experiente, ou sem indicação de fonte bibliográfica, subtendendo um conhecimento geral da categoria amplamente compartilhado.

Assim como o passo "Indicando filiação teórica da pesquisa", o passo Definindo conceitos é tipicamente realizado na seção de Fundamentação teórica, como evidenciado na pesquisa de Rio Lima (2016). Logo, a sua realização na seção de Identificação do problema de pesquisa provavelmente vem indicar que o pesquisador busca mostrar para a banca avaliadora que ele tem conhecimento dos conceitos chaves que integram sua pesquisa.

As pistas linguísticas que indicam o reconhecimento do passo em questão, além dos nomes das próprias categorias, foram: "infere-se", "lemos que", "se caracteriza" e "constitui". A diante, veja um exemplo:

Infere-se que a língua falada, observada, descrita e analisada em seu contexto social, torna- se o objeto de estudo da Sociolinguística, tendo como ponto de partida, uma comunidade de fala, que nas palavras de Alkmim (2012, p. 33) é "um conjunto de pessoas que interagem verbalmente e que compartilham um conjunto de normas com respeito aos usos linguísticos". A autora esclarece, ainda, que toda comunidade de fala se caracteriza por diferentes modos de falar, a considerar 0 nível fonético-fonológico, morfossintático e lexical.

8VDL2019

No exemplo acima, o autor define o conceito de comunidade de fala através das palavras de Tânia Alkmim, isto é, indicando fonte bibliográfica. Além de apresentar também como uma comunidade de fala se caracteriza.

O passo retórico Indicando problemas no mundo social ocorreu em quatro projetos de pesquisa e é utilizado para apresentar problemas de ordem prática, como os relacionados ao ensino nas escolas, por exemplo. Tais problemas potencialmente são minimizados ou solucionados com o desenvolvimento da pesquisa. Em nosso corpus, esse passo manteve uma relação com o "Recomendando e/ou prescrevendo ação empírica", visto que em três de suas realizações, os autores apresentaram um problema de ordem prática e também uma recomendação.

Como observado em Rio Lima (2019), os problemas podem ou não ter uma mediação de leitura. O problema apresenta mediação de leitura quando é construído 
baseado em referências (pesquisas prévias ou dados estatísticos, por exemplo). Essa mediação indica que o problema levantado pode ser confirmado, como nos exemplos descritos abaixo.

Em 02AD2019, o autor apresenta o problema (dificuldades de aplicar conhecimentos teóricos na sala de aula) com base em dados estatísticos (indicadores de desempenho), além de apontar que existem poucos estudos voltados para a problemática.

Apesar dessa evolução, ainda são nítidos o baixo rendimento dos estudantes e a dificuldade dos professores relacionada à aplicação prática de conhecimentos teóricos linguístico-discursivos em salas de aulas. Especialmente, no Ensino Médio, esse cenário é mais complexo, porque os indicadores de desempenho acadêmico estão abaixo dos padrões mínimos e os estudos voltados especificamente para o ensino de língua materna nesse segmento são incipientes

02AD2019

Em 11LET2019, o autor evidencia o problema na educação brasileira com base nos resultados publicados pelo INEP.

\begin{abstract}
Segundo os dados mais recentes publicados pelo Instituto Nacional de Estudos e Pesquisas Educacionais Anísio Teixeira - INEP (BRASIL, 2018), no que diz respeito ao Exame Nacional do Ensino Médio (ENEM), a média geral apresentada pelos candidatos na área de Linguagens, Códigos e suas Tecnologias corresponde a 526,9 pontos e, em Redação, 522,8 pontos. Tais números, medianos, demonstram que as atividades envolvendo leitura e escrita no Ensino Médio, especialmente nas redes públicas de educação, não estão cumprindo satisfatoriamente os objetivos propostos pelas diretrizes curriculares neste nível da escolarização básica.
\end{abstract}

11LET2019

Algumas das pistas linguísticas observadas para a identificação do passo foram: "Impensável", "o baixo rendimento", "segundo os dados".

O passo Levantando hipóteses apresentou sete ocorrências em cinco projetos de pesquisa e é utilizado para apresentar hipóteses para as questões problemas levantadas na seção. Hipóteses são postulados teóricos sobre o problema ou possíveis respostas para os questionamentos propostos (MOTTAROTH; HENDGES, 2010). Lembrando que hipóteses são respostas ou teses provisórias, podendo ou não serem validadas com a realização da pesquisa. É como se o pesquisador imaginasse como será sua trajetória em busca de respostas para o seu problema. Nesse sentido, Luna (1998, apud MOTTA-ROTH; HENDGES, 
2010) diz que as hipóteses são provisórias e precisam de confirmação por evidências para que sejam mantidas. É por essa razão que, durante o desenvolvimento da pesquisa, novas hipóteses podem surgir. Veja um exemplo:

Como hipótese inicial, acredita-se que há sim um distanciamento entre a prática de ensino e a BNCC, por duas razões: o documento é recente, logo poucos professores o conhecem a fundo, e as aulas de português ainda privilegiam o ensino tradicional da gramática normativa, porque o professor se sente mais "confortável" em fazer análises sintáticas no quadro do que realizar atividades de leitura e produção de texto, o que requer maior planejamento e tempo de trabalho.

09GL2019

Em 09GL2019, o autor apresenta a hipótese de que há um distanciamento entre a prática de ensino e a BNCC, além de apresentar motivos que contribuíram para a construção dessa hipótese.

A partir da apreciação qualitativa, notamos que os pesquisadores buscam elaborar hipóteses próprias para os questionamentos apresentados, possivelmente com o intuito de mostrar para a banca avaliadora que são capazes de fazer projeções sobre o objeto de estudo e os problemas de pesquisa. As principais pistas linguísticas que indiciadoras da identificação do passo levantando hipóteses foram: "hipótese", "tese", "parte-se do pressuposto", "seguinte pressuposto".

O passo retórico Indicando possíveis benefícios ocorreu em quatro projetos de pesquisa analisados e é utilizado para indicar os benefícios ou contribuições da pesquisa. A realização desse passo tem caráter persuasivo e os doutorandos fizeram uso dele com o intuito de convencer a banca avaliadora de que seu projeto de pesquisa poderá ter benefícios.

Quantos às pistas linguísticas que apareceram nas realizações do passo, todas apresentaram o verbo "contribuir". Veja alguns exemplos:

Em 01LTX2019, o autor apontou que os resultados da pesquisa poderão contribuir com novos enfoques teóricos e metodológicos.

A sistematização, análise e interpretação destes dados poderá contribuir com novos enfoques teóricos e novas metodologias de descrição e análise de gêneros institucionais.

01LTX2019 
Ao passo que em 03GL2019 foi apontada como possível contribuição uma reflexão acerca da constituição do pensamento intelectual de linguistas piauienses.

Busca-se, com o desenvolvimento da pesquisa, contribuir para a reflexão de como se constituiu o pensamento intelectual na área da Linguística no Piauí e que processos o favoreceram e atuaram nessa implantação.

03GL2019

No projeto 12GL2019, o autor apontou como possível contribuição o entendimento de como se deu a recepção e o estabelecimento de teorias no interior do programa institucional (PPGEL-UFPI).

Verificar os diferentes movimentos que contribuíram para a formulação do conhecimento linguístico no PPGEL/UFPI, não só valoriza o processo histórico envolvido, como também contribui para o entendimento de como se deu essa construção e de que modo a produção e a recepção de teorias, a partir de influências teóricas e grupos de especialidade formados, se estabeleceram pelo programa institucional.

12GL2019

O passo Delimitando corpus e/ou fonte do corpus da pesquisa apresentou quatro ocorrências em quatro projetos do corpus. Trata-se de um passo típico da seção de metodologia e tem por função descrever o corpus da pesquisa ou a fonte, que, dependendo da subárea e do viés metodológico, pode sofrer variações.

Quanto às pistas linguísticas, identificamos o uso do próprio termo "corpus", bem como os verbos "constituir", "mapear" e "investigar". As realizações desse passo em nossa amostra se deram de forma breve e às vezes em conjunto com outro passo. A seguir, um exemplo de como o passo é realizado:

O corpus será constituído por fontes documentais diversas, quais sejam: livros, prefácios, revistas piauienses, entrevistas com figuras que atuaram no período examinado, só para citar alguns.

03GL2019

A partir da análise realizada, observamos que a principal ação retórica desenvolvida na seção de "Identificação do problema de pesquisa" é apresentar o problema de pesquisa. Em nosso corpus, essa ação foi realizada por meio das estratégias retóricas materializadas nos passos já descritos. Sendo dois passos retóricos de alta recorrência: Formulando questões norteadoras de pesquisa e 
Apresentando objetivos da pesquisa. Assim, podemos estabelecer relações entre esses dois passos e a ação retórica de apresentar um problema. Dessa forma, a seção é construída voltada para um ou mais questionamentos que poderão ser respondidos com a realização da pesquisa. Os pesquisadores também reiteram os objetivos da pesquisa, acentuando a relevância da mesma e apontando caminhos para resolução da problemática de estudo.

\section{Considerações finais}

Nesse estudo, buscamos analisar como se deu a organização retórica da seção destinada à identificação do problema de pesquisa em projetos de pesquisas de Linguística, identificando e descrevendo os passos retóricos mais recorrentes do corpus. Evidenciamos a recorrência de quinze passos retóricos, sendo que todos já haviam sido descritos em pesquisas anteriores. A seção se mostrou bastante heterogênea, servindo como uma "porta de entrada", apresentando estratégias de aspectos teóricos, metodológicos e empíricos. Assim, os pesquisadores parecem se apropriar de conhecimentos teóricos disponíveis e articular com suas experiências a fim de apresentar uma problemática.

Como esperado, a seção de identificação do problema de pesquisa é construída com o intuito de propor questões de pesquisa que possivelmente serão respondidas com o desenrolar das investigações. Através das análises, constatamos que o passo "Formulando questões norteadoras da pesquisa" apareceu em onze projetos (dos doze analisados). O segundo passo de maior recorrência foi o "Apresentando objetivos da pesquisa" por meio do qual os autores reiteram os objetivos, agregando relevância a pesquisa e apontando caminhos para investigar o problema. Em seguida, estão os passos "Indicando a filiação teórica da pesquisa" e "Reivindicando a relevância do objeto de estudo" que apareceram em seis projetos.

Evidenciamos também a baixa recorrência dos passos "Indicando lacuna de pesquisa" e "Relatando pesquisa prévia", o que diz muito sobre o fazer cientifico da área, demostrando que os autores não procuram identificar lacunas ou refutar pesquisas prévias, dedicando-se a reforçar conhecimentos teóricos relativamente estáveis. Não se trata de um ponto positivo ou negativo, apenas mostra que algumas culturas disciplinares não têm como foco preencher lacunas de estudos prévios, havendo preferência em analisar como as teorias se comportam na prática. 
Cabe aqui também apontar algumas limitações da nossa pesquisa, como o fato do nosso corpus ter sido bem reduzido ou não analisarmos o contexto de produção dos projetos, pois não tivemos como realizar entrevistas com os envolvidos no processo de produção do gênero. Assim, seria interessante em estudos futuros analisar um corpus maior (a fim de obter resultados melhores), bem como coletar informações de como os usuários entendem o gênero projeto de pesquisa. Além disso, seria relevante também analisar as subáreas da linguística e entender como cada uma lida com a construção da seção, analisando uma quantidade igual de projetos para cada subárea. Esperamos que esse trabalho possa contribuir para os estudos do gênero.

\section{Referências Bibliográficas}

ALVES FILHO, F. Gêneros jornalísticos: notícias e cartas de leitor no ensino fundamental. São Paulo: Cortez, 2011.

ALVES FILHO, F. Como mestrandos agem retoricamente quando precisam justificar suas pesquisas. Revista Brasileira de Linguística Aplicada, v. 18, n. 1, 2018.

ALVES FILHO, F. RIO LIMA, C. A. C. A motivação para a proposição de pesquisas por pesquisadores de linguística: uma análise sociorretórica. Fórum Linguístico, v. 17, p. 4860-4877, 2020.

ASKHAVE, I; SWALES, J. M. Identificação de gênero e propósito comunicativo: um problema e uma possível solução. In: BEZERRA, Benedito Gomes; BIASIRODRIGUES, Bernardete; CAVALCANTE, Mônica Magalhães (orgs). Gêneros e sequências textuais. Recife: Edupe, p.221-243, 2009..

BARROS, J. d'A. O Projeto de Pesquisa em História: da escolha do tema ao quadro teórico. Petrópolis: Vozes, 2005.

BAKHTIN, M. Os gêneros do discurso. Rio de Janeiro: Editora 34, 2016.

BAZERMAN, C. Gêneros textuais, tipificação e interação. São Paulo: Cortez, 2005.

BAZERMAN, C. Retórica da ação letrada. São Paulo: Parábola Editorial, 2015.

GIL, A. C. Como elaborar projetos de pesquisa. 4ํe ed. São Paulo: Atlas, 2002.

HEMAIS, B.; BIASI-RODRIGUES, B. A proposta sociorretórica de John M. Swales para o estudo de gêneros textuais. In: MEURER, JOSÉ LUIZ; BONINI, ADAIR; MOTTA-ROTH, DESIRÉE. (Org.). Gêneros: teorias, métodos, debates. Rio de Janeiro: Parábola Editorial, p. 108-129, 2005. 
HENDGES, G. R. Novos contextos, novos gêneros: a revisão da literatura em artigos acadêmicos eletrônicos. 2001. 138 f. Dissertação (Mestrado em Letras) Universidade Federal de Santa Maria, Rio Grande do Sul, 2001.

MARCUSCHI, L. A. Produção textual, análise de gêneros e compreensão. São Paulo: Parábola Editoria, 2008.

MONTEIRO B. N. Organização retórica e estruturação sequencial da seção de metodologia do gênero projeto de pesquisa. 2016. Dissertação (Mestrado em Letras) - Universidade Federal do Piauí, Teresina, 2016.

MOTTA-ROTH, D.; HENDGES, G.R. Produção textual na universidade. São Paulo: Parábola Editorial, 2010. Série Estratégias de ensino.

MILLER. C. R. Gênero como ação social. In: DIONISIO, Angela paiva; HOFFNAGEL, Judith Chambliss (orgs.). Gênero Textual, agência e tecnologia: estudos. São Paulo: Parábola Editorial, p.21-41, 2012..

OLIVEIRA, J. S. L. Como mestrandos de linguística agem retoricamente quando elaboram sua identificação do problema de pesquisa. 2019. $54 \mathrm{f}$. Trabalho de Conclusão de Curso (Monografia) - Licenciatura em Letras - Língua Portuguesa e Literatura de Língua Portuguesa, Universidade Federal do Piauí - UFPI, Teresina, 2019.

OLIVEIRA, J. S. L. ALEXANDRE, L. R. B. Como mestrandos de linguística agem retoricamente quando elaboram sua identificação do problema de pesquisa. Letras em revista, [S.I.], v. 11, n. 01, jun. p. 219-235, 2020.

RIO LIMA, C. A. C. Movimentos Retóricos da Seção de Fundamentação teórica de Projetos de pesquisa da área de História. Teresina: PIBIC, 2016. (Não publicado).

RIO LIMA, C. A. C. Estratégias retóricas do gênero projeto de pesquisa nas áreas de linguística e química: relatando pesquisas prévias, indicando lacuna de pesquisa e problemas do mundo real. 2019. 161 f. Dissertação (Mestrado em Letras) Universidade Federal do Piauí, Teresina, Piauí, 2019.

SILVA, C. R. B. ALVES FILHO, F; OLIVEIRA, V. G. "Criando um problema": a escrita da seção de identificação/caracterização do problema nas áreas de Linguística e Química. Investigações (ONLINE), v. 33, p. 1-27, 2020.

SILVA, C. R. B. ALVES FILHO, F. A organização retórica da seção de Justificativa de projetos de pesquisa de tcc em contextos de produção distintos. Letras em revista, v. 11, p. 201-218, 2020

SWALES, J. M. Genre Analysis: English in academic and research settings. Cambridge: Cambridge University Press, 1990.

SWALES, J. M. Research Genres: Explorations and Applications. Cambridge: Cambridge University Press, 2004. 